\title{
水利工程施工中堤坝防渗加固技术的探讨
}

\author{
任世华 \\ 海阳市水利局 \\ DOI:10.32629/hwr.v4i7.3188
}

\begin{abstract}
[摘 要] 现如今, 我国水利工程建设得到快速发展, 在水利工程施工建设期间, 加强堤坝防渗加固也成为 工程施工中最为重要的内容。利用科学合理的加固技术可显著提高工程建设的质量,进而全方位发挥出 水利工程建设的经济效益、社会效益和环境效益,促进社会的长期稳定发展。
\end{abstract}

[关键词] 水利工程; 堤坝防渗加固技术; 经济效益; 环境效益

如今, 我国社会经济发展进程日益 加快, 同时, 水利工程的规模也在不断扩 大, 水利工程施工技术日益多样化。堤坝 施工是水利工程施工中极为关键的组成 部分, 为了有效规避堤坝渗漏问题, 就需 要合理应用防渗加固技术, 推动行业的 长期、稳定发展。

\section{1 水利工程堤坝险情分析}

堤坝在水利工程施工中发挥着至关 重要的作用, 其施工难度较大, 且工艺较 为复杂, 如堤坝施工技术水平不达标, 则 会产生十分明显的安全和质量隐患。另 外, 水利工程进入使用阶段后, 堤坝处于 长时间受冲击和腐蚀的状态, 因此也引 发了大面积坑槽或损坏等问题。

调查显示, 我国很多地区的水利工 程运行中, 坝体裂缝、滑坡和堤坝防漏等 问题是较为常见的险情。坝体裂缝对水 利工程的稳定性产生了十分显著的影响, 如坝体裂缝内积存大量的水分, 则会加 速钢筋的腐蚀。水利工程若出现坝体滑 坡问题, 会直接威胁到工程的安全平稳 运行。

堤坝渗漏主要分为坝基渗漏和堤身 渗漏。水利项目施工中, 选择的坝基基础 施工工艺不够科学。其中, 基础强度和刚 度较低是引发坝基渗漏的主要因素。在 运行后期也会出现基底渗透等问题。堤 身渗漏与堤坝施工中使用的石块和细砂 密实度不足, 坝基与堤身间连接区域未 采取有效措施开展施工处理, 进而引发 渗漏, 坝体不稳定, 最终水利工程运行中
出现了堤坝渗漏问题。

\section{2 堤坝防渗加固技术在水利工} 程施工中的应用

2. 1 渗漏涌水处理技术

2.1.1导管注浆

对于局部渗漏问题, 在工程建设和 施工中可采用导管注浆法, 并且在指定 位置放置适量高聚物注浆材料, 使其充 分膨胀, 有效填充土体的孔隙和接触缝 隙。在挤密施工中, 应适当加大土体的密 实度, 从而加强结构的稳定性, 建成较为 坚固的防渗体系。导管注浆技术在坝基、 坝肩渗漏和涵闸渗漏处理中均发挥着重 要的作用。

\subsection{2膜袋注浆和封堵管涌}

该技术充分利用膜袋的膨胀作用， 以较短的时间封堵涌水, 同时也可结合 实际合理使用注浆材料实现袋内膨胀, 之后填充管涌入口。应用膜袋注浆能够 改进管涌通道封堵的质量, 以此加强防 渗的效果。

\section{2防渗墙技术}

2.2.1高压喷射法

高压喷射法主要利用高压喷射设备, 由高压喷嘴喷射水泥, 合理利用高压冲 击力扰动坝基的覆盖物。在喷射施工中, 水泥直接灌入坝基, 也可搅拌砂土。水泥 砂浆凝结后, 自坝基向上形成防渗墙, 进 而加强阻水防渗的效果。该技术在工程 施工中应用范围较广, 且在科学技术发 展中, 也在不断寻求创新, 高压喷射法技 术操作便捷, 成本投入较少, 有着较为理
想的防渗效果。

\subsection{2自凝灰浆法}

自凝灰浆法的发展时间较短, 国 内依然处于探索阶段。现阶段自凝灰 浆法不够成熟, 工程施工中需要在混 凝土中加入适量的缓凝剂, 从而在自 制砂浆且砂浆凝固的过程中形成防渗 墙。工程施工中, 若要造孔, 则需要在 砂浆凝固前完成, 以免孔沿破坏工程 的防渗性能。

\subsection{3水泥搅拌桩法}

水泥搅拌桩技术是堤坝施工中较为 常用的技术形式。工程人员需利用搅拌 机搅拌水泥, 水泥在搅拌中也会产生化 学反应, 凝固时, 水泥的硬度明显提高, 水泥与土体充分结合, 从而形成十分坚 固的防渗墙。该技术主要应用在填充沙 砾和土质地基当中, 且其在墙体防渗方 面也具有较为理想的效果, 一方面改进 了防渗质量, 另一方面也加强了地基结 构稳定性。

2. 3灌浆防渗措施

2. 3. 1 繴裂帷幕灌浆技术

䢃裂帷幕灌浆技术是在加固堤身 基础上而衍生出的施工技术。由于坝体 的曲直存在明显的差异, 钻机的形式也 有所不同, 浅孔钻机主要应用梅花形布 孔方式, 沿堤坝直线从顶部向外钻孔 $1.5 \mathrm{~m}$, 要求孔距不得超过 $3 \mathrm{~m}$ 。且工程施 工中需结合工程实际情况加以调整, 差 距应在 $1-2 m$ 。工程建设期间, 也可选择 直线布孔的方式, 由上而下灌浆, 这样 
可有效控制压力, 避免灌浆过程中出现 漏浆或滑坡问题, 应用上述方法可显著 提高坝基的施工质量, 避免出现堤坝渗 漏问题。

\section{3. 2 低压速凝灌浆技术}

低压速凝灌浆技术广泛应用在高危 水位堤坝抢险工作中, 技术人员需要结 合管涌实际, 科学选择钻孔。首先, 要向 孔内灌入适量的水泥砂浆, 确保所选水 泥膨胀后压力在 $49 \mathrm{kPa}$ 以内。其次, 合理 注入适量的膨胀物质, 以此有效增大管 涌内的阻力, 防止水泥流出。最后, 加入 适量的速凝剂, 缩短凝固的时间, 之后封 堵管涌。

\subsection{3高压填充灌浆技术}

结合堤坝实际采取高压填充灌浆施 工技术, 填充堤身的漏洞。灌浆施工中可 充分利用长度为 $50 \mathrm{~m}$ 的工程钻钻入, 并且 将孔距设置在 $1.5-2 \mathrm{~m}$, 确定最佳深度。这 就要求人员在灌浆施工中合理控制压力, 套管进入底层后, 需保证堤身的干燥。在 沙砾层灌入适量的水泥砂浆, 随后缓慢 提升, 以此填补堤身的漏洞。

\section{3. 4 灌浆加固措施}

灌浆加固技术主要应用在浆砌石重 力坝的施工中, 其能够加固坝上油面灌 浆施工, 有效防止漏洞和裂缝的进一步 发展, 而且也可以增强坝体的稳定性, 优 化结构的防渗性能, 增大结构的承载力。 若坝体稳定性不足, 则会埋下十分严重 的风险隐患。如下游位置不稳定, 会引发 斜孔、水平孔等问题, 且在灌浆施工中也 会出现漏水管堵塞和坝体空间等问题。 在工程建设和施工中, 为避免上述问题 的产生, 需要使用反向灌注施工技术改 善坝面的稳定性和抗冲击能力。

\section{3 完善堤坝防渗加固技术的有 效措施}

堤坝是水利工程的重要组成结构, 做好其防渗加固工作, 有助于水利工程 项目质量与安全保证, 为此, 我们应加强 此方面重视。具体可以, 可以采取以下几 种措施:

3. 1 优化堤坝防渗体系, 落实堤坝加 固方案

水利工程建设和施工中, 若要采取 有效措施完善堤坝防渗技术, 首先, 要利 用有效措施优化防渗加固体系, 编制且 贯彻堤坝加固方案。在优化和完善䢃裂 灌浆施工法的过程中, 工作人员应当结 合堤坝的弯曲程度选择不同的工具, 从 而改进水利工程施工的效率, 有效规避 堤坝渗漏问题。

其次, 高度落实和完善工程的防渗 加固施工方案, 充分发挥防渗加固施工 的作用, 提高防渗加固施工的经济效益 和社会效益。为此, 工程人员要深入分 析现阶段堤坝防渗工作中存在的问题, 同时针对不同的问题采取切实可行的 解决措施。再者, 依据堤坝防渗加固施 工的基本原则, 采取科学有效的防渗加 固技术, 参照工程的实际情况, 采取有 针对性的预防处理措施, 如防渗和灌浆 施工等方式, 妥善处理滑坡问题。采取 上述措施做好堤坝防渗加固施工, 能够 在加快堤坝施工进度的同时, 有效增大 堤坝结构的整体强度, 进而改善整体工 程的建设水平。

\section{2 清除滑坡, 治理崩岸}

受内部渗水、上方重压以及流水冲 刷等因素的影响, 堤坝极易出现滑坡问 题, 如堤坝出现滑坡现象, 则要求施工人
员先完善堤坝的排水与防渗工作, 以此 减轻因滑坡现象所引发的各项损失。施 工阶段, 施工人员务必及时清理滑体, 并 且重新填筑。与此同时, 适当增加阻滑体, 加强堤坝坡体的稳定性。此外, 还应加强 对崩岸的处理, 出现崩岸后, 河床会出现 横向变形。这里施工人员需采取抛石湖 泊处理方式, 展开全方面的控制, 并在基 础和抛石间铺设土工织物反滤层, 或者 也可利用木桩、沉排和丁坝等方式, 做好 治理工作。

\section{4 结束语}

结合上述内容可以看出, 为有效控 制水利提防工程中的渗漏问题, 施工单 位应当充分结合水利堤防工程概况, 选 择适宜的防渗加固施工技术。严格控制 工程施工质量, 正确认识渗漏对堤防工 程的负面影响。技术人员还需不断提升 自身的技术能力和专业素养, 注重对防 渗加固技术的全方面管理, 以此促进我 国水利行业的可持续发展, 并最终为社 会的发展建设创造理想的效益。

\section{[参考文献]}

[1]果丽. 水利工程中堤坝防渗 加固技术的应用 [J]. 科学技术创 新,2018,(4):125-126.

[2]邢磊.水利工程施工中堤坝防渗 加固技术应用及质控要点分析 [J].中国 高新区,2018,(008):200。

[3]王义兴.水利工程施工中堤 坝防渗加固技术的运用 [J]. 陕西水 利,2018,(003):199-200.

[4]黄丽珠.水利工程施工中堤坝防 渗加固技术的应用[J].科技创新与应 用,2013,(029):204-205. 